\title{
ASSESSMENT AND MITIGATION OF AGRICULTURAL VULNERABILITY IN INDIA USING GLOBAL DATASETS
}

\author{
Kaushalya Ramachandran ${ }^{1}$, Shubhasmita Sahani $^{2}$, D.V.S.Sarma ${ }^{3}$, V. Praveen Kumar ${ }^{4}$ \\ ${ }^{I}$ Principal Scientist \& ICAR National Fellow \\ kausalya@crida.in \\ ${ }^{2}$ RA - ICAR National Fellow scheme \\ sahanishubhasmita@gmail.com \\ ${ }^{3}$ SRF- ICAR National Fellow scheme \\ sardevar@gmail.com
}

${ }^{4}$ SRF- NICRA scheme, Central Research Institute for Dryland Agriculture, ICAR, Santoshnagar, Hyderabad - 500059 vaddikv@gmail.com

\begin{abstract}
Global datasets of NDVI data products obtained from NOAA-AVHRR and MODIS-TERRA (1982-2012) satellites were used to assess agricultural vulnerability in India for which a methodology was developed. Use of bio-physical indicators like NDVI to assess agricultural vulnerability adds a new dimension to this field of research dominated by socio-economic analysis. Timeseries vegetation index data from NOAA-AVHRR and MODIS - TERRA satellites (1982 to 2012) provided a valuable insight into the slow and imperceptible impact of climate change on variations in length-of-crop-growing-period, cropping pattern and agricultural production systems besides changes in vegetation cover, land use and on agricultural sustainability in rainfed regions where millions of small and marginal farmers subsist on small holdings.
\end{abstract}

A study was carried out using tools and techniques of Geo-informatics that formed the basis for a comprehensive assessment of agricultural vulnerability in India to assess the sensitivity of agricultural systems, it's exposure to climate hazards and to ascertain the adaptive capacity of farmers to withstand climatic stresses. Till date there are no comprehensive studies reporting the use of bio-physical indicator like vegetation index and tools of geo-informatics to assess agricultural vulnerability. Hence this study is unique as it has for the first time indicated that of the 74 million ha (Mha) under agriculture in 122 districts in India, over 47 Mha of Net Sown Area was vulnerable to climate change. Coarse AVHRR NDVI dataset indicated that over 29 Mha of Net Sown Area, an underestimation due to difficulty in classifying mixed pixels at coarse resolution. Notwithstanding variations in the spatial extent estimated, it is notable that nearly 1/5th to 1/3rd of Net Sown Area in India out of a total of 142 Mha was vulnerable to climate change.

Rainwater harvesting and its use for supplementing irrigation through watershed projects have shown promise and could help in improving adaptive capacity of farmers. Information on spatial extent of agricultural vulnerability and types of hazards impacting agriculture could help in prioritizing and targeting implementation of development projects for agriculture. Free access to global datasets and open-source GIS has facilitated this study. Finer resolution datasets could greatly improve accuracy of estimation of agricultural vulnerability in India and elsewhere.

Keywords: Geo-informatics, agricultural vulnerability, climate change, NDVI, LGP, watershed development program ****.

\section{INTRODUCTION}

Climate change studies predominates the present national and international dialogue due to frequent occurrences of aberrant weather conditions and increased frequency of extreme weather events like drought, floods, hail storms, cyclones, heat and cold wave. Scientific community opine that anthropogenic causes like increasing GHG emissions is the cause for growing weather aberrations (IPCC, 2007a, 2012, 2013; US-EPA, 2014) besides large scale change in Land Use - Land Cover (LULC) that impact the state and vigour of vegetation and crop thus adversely affecting agricultural potential of a region.
By and large vulnerability of human society or a sector to climate change have been studied using socio-economic approach (Adger and Kelly, 1999; Aguilar et al.,2012) or bio-physical approach or using an integrated approach combining both the above-stated methods (IPCC, 2007). IPCC has defined vulnerability as the degree to which a system is susceptible to, or unable to cope with, adverse effects of climate change (Fischer et al., 2002; TERI, 2003), including climate variability and extremes. Thus vulnerability is considered to be a function of the character, magnitude and rate of climate variation to which a system is exposed, its inherent sensitivity, and its adaptive capacity that enables recovery and /or capability to withstand impact. 
It has largely been agreed that analysis of adaptive capacity is supported by socio-economic approach and the study of sensitivity by biophysical approach as both are internal dimensions of an ecosystem while the aspect of exposure deals with external dimensions or occurrence of bio-physical phenomena like drought, flood or cyclone alone. However an integrated approach is what is desirable to address the issue of climate change although there are severe limitations in the present state of knowledge and understanding due to inherent issues of scales, linkages, telescoping connections, and scenarios of future projections and lack of authentic datasets (de Sherbinin- USAID, 2014).

The Indian Council of Agricultural research (ICAR) initiated a national program for study of climate change in 2011 under the banner - National Initiative on Climate Resilient Agriculture (NICRA) to assess agricultural vulnerability in India in order to develop strategies for improving mitigation and adaptation among farmers.

\section{OBJECTIVES}

A study was undertaken at CRIDA at Hyderabad under NICRA to assess the issues related to sensitivity of rainfed agriculture in India and the impact of climate change on it. To study these aspects geospatial tools and techniques were used and global datasets of vegetation index (Normalized Difference Vegetation Index, NDVI) derived from satellite data was used as an indicator to understand climate change phenomena that adversely impact rainfed agriculture making the dependant population, livestock and economy in India vulnerable. Use of weather variables like precipitation and temperature helped in understanding the genesis and impact of extreme weather events and resultant LULC and NDVI changes. The tools and techniques of remote sensing and GIS facilitate in examining the impacts of weather aberrations, abrupt extreme events and slow creeping changes on bio-physical cover of earth.

\section{MATERIAL \& METHODS}

Temporal study of NDVI variations was carried out using Global Datasets of NDVI data products from Advanced Very High Resolution Radiometer (NOAA-AVHRR) (15day, $8 \mathrm{~km})$ and Moderate Resolution Imaging Spectroradiometer (MODIS-TERRA) (16-day, 250m). Time-series NDVI datasets were downloaded from the respective websites and used to assess sensitivity of cropping systems in various agro-eco-regions in India in order to map agricultural vulnerability in the country. GIMMS (Global Inventory Modelling and Mapping Studies) dataset of NOAA- AVHRR with $8 \mathrm{~km}$ resolution composited at 15 days interval, was used to analyse sensitivity of agricultural systems in India at state (unit for federal administration) and agro-eco-sub-region (AESR) level for 1982-2006, while MODIS - TERRA NDVI data product with a higher spatial resolution of $250 \mathrm{~m}$ was used to assess agricultural sensitivity at the district-level (2001-2012) which is the lowest unit for administration in India. Standard Precipitation Index (SPI) estimated from actual rainfall data was used to corroborate sensitivity of agriculture to climate variations and incidence of extreme weather events during the study period (Mckee et al., 1993; Tucker et al., 1985; Thenkabail et al., 2004; Dadhwal, 2011; SeshaSai et al., 2011; Murthy et al., 2008; Murthy and SeshaSai 2011).

\subsection{Methodology for Assessing Agricultural Vulnerability}

A methodology was developed to assess agricultural vulnerability using global datasets of NDVI data. NDVI data products of NOAA-AVHRR series of satellites available as 15-day composites at $8 \mathrm{~km}$ resolution for the period 1982 to 2006 and from MODIS -TERRA series of satellites available as 16-day composites at $250 \mathrm{~m}$ resolution for the period 2001 to 2012, were downloaded from NASA-USGS site. NDVI data products are pre-processed for scale, cloud cover, water vapour and missing data. The data was assessed for quality and stacked to produce annual NDVI image for 1982 - 2012. The data stacks were smoothened using Savitzky - Golay technique. Permanent vegetation, water body, snow, built-up area and desert sand were masked to eliminate them from analysis. Co-efficient of Variation (CV) of Max NDVI was estimated by using modeller in ERDAS Imagine software and degree of agricultural vulnerability was estimated as follows: CV of $10-20 \%$ was termed mildly vulnerable; 20-30 \% termed moderately vulnerable while $>30 \%$ was termed severely vulnerable.

\subsection{Methodology for Estimating Length-of-Crop-}

\section{Growing-Period (LGP)}

Information on normal LGP derived from water-balance model for each AESR based on several station data are available (Velayutham et al., 1999). To understand variations in LGP based on NDVI, a seasonal NDVI Threshold Value for Kharif (SW Monsoon season) and Rabi (NE Monsoon period) seasons was identified derived using Mean NDVI value for three normal rainfall years viz., 1986, 1991 and 1999 (Kausalya et al., 2014a,b,c). This Threshold Value (TV) was then used to verify changes in LGP at AESR-level. Cropping season-wise LGP was assumed to start when NDVI value crossed the TV and continued in an upward trend. Similarly, LGP was considered to end when NDVI fell below TV and continued in a downward trend. Season-wise sum of stacked images were imported and multiplied with a factor of 15 or 16 (i.e., no. of days) to obtain a LGP map.

\subsection{Methodology to estimate Standard}

\section{Precipitation Index (SPI)}

SPI is a better tool to analyse and corroborate a climatic event or extreme weather situation compared to actual rainfall (Mckee et al., 1993). Available district- wise daily rainfall data for 1982 - 2011 was converted to monthly rainfall using Weather Cock software (V1.0) (CRIDA, 2011). Derived SPI was plotted for each AESR by kriging using Spatial Analysis Tool in ArcGIS 10.3. 


\section{RESULTS AND DISCUSSIONS}

\subsection{Variations in NDVI or Vegetation Index In}

\section{India}

Seasonal NDVI was studied using Mean and Max NDVI values for Kharif (SW monsoon) and Rabi (winter) cropping seasons in the form of a continuum for 1982-83 and 20052006 as indicated in Figure 1. Kharif cropping season in 1982-83 started in 1st week of May 1982 instead of June as is normal and ended in first week of November in 1982 while the Rabi season started in 1st week of November 1982 and ended in the last week of March 1983.

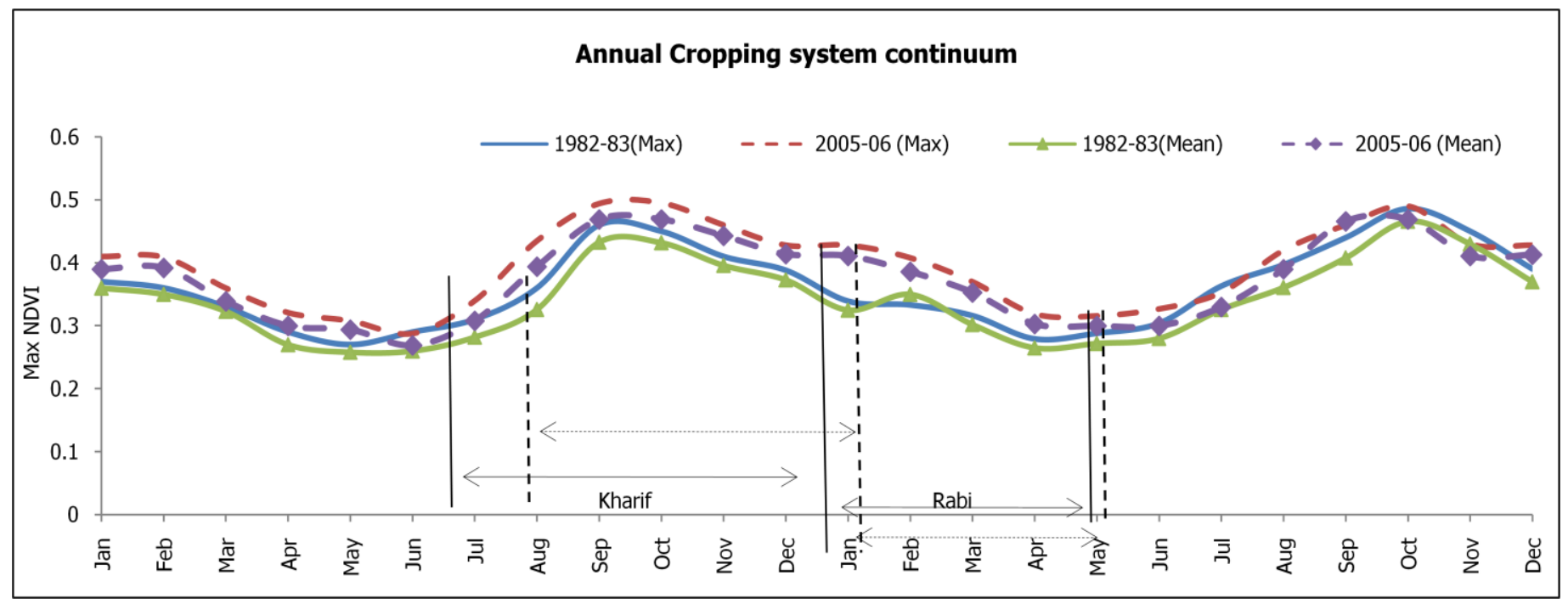

Figure 1: Shift in seasonal Max NDVI during cropping seasons indicating a change in cropping window.

In 2005 the Kharif season started in 2nd week of June 2005 and ended in last week of November 2005. Rabi season started in 1st week of December 2005 and ended in the last week of March, 2006. Thus, we see a delay in the start of both Kharif and Rabi cropping seasons in 2005-2006 and an effective reduction in length of cropping seasons during Kharif and Rabi. Variability in Start of Cropping Season (SOS) - both during Kharif and Rabi cause a reduction in phenological growth of crop at various stages; require new seed varieties suitable for the new crop window, thus adversely affecting agricultural production in the country.

\subsection{Estimating Extent of Agricultural Vulnerability in India}

Using global datasets of AVHRR and MODIS NDVI data products, it was possible to estimate the spatial extent of vulnerable regions in India based on coefficient of variation (CV) of Max NDVI using the methodology indicated earlier. This information is useful for developing strategies to mitigate impact of climatic aberrations. CV of Max NDVI at each pixel -level was estimated and a vector layer of AESR, state and district boundary was overlaid to estimate extent of agricultural vulnerability.

Study of MODIS-TERRA NDVI dataset indicated that over 47 million ha (Mha) of Net Sown Area (NSA) or 33.1\% of the country's agricultural land is vulnerable to climate change. Figure 2 depicts the extent of agricultural area vulnerable to climate change. It was seen that over 122 districts in the country were vulnerable to climate change. Based on CV of Max NDVI it was seen that over 39 Mha was mildly vulnerable (CV 10-20\%), 5.6 Mha was moderately vulnerable (CV 20-30 \%) and over 1.4 Mha was severely vulnerable (CV of $>30 \%$ ) to it. Study using coarse dataset of NOAA-AVHRR with $8 \mathrm{~km}$ resolution indicated that over 29 Mha or $20.4 \%$ of net sown area was vulnerable.

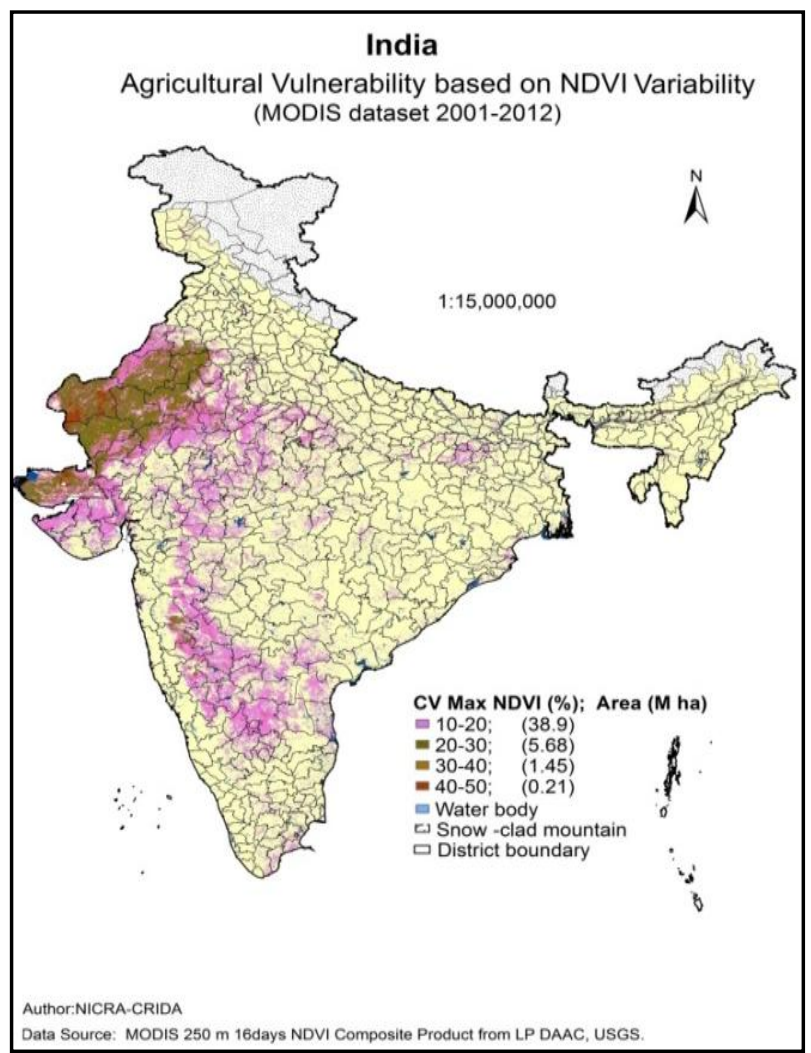

Figure 2: Extent of agricultural vulnerability at district-level based on MODIS NDVI dataset. 


\subsection{Typology of Vulnerability Based on Prevalent}

\section{Major Cropping Systems}

Cropping systems prevalent in the vulnerable districts identified based on CV of Max NDVI were analyzed and typologies were drawn in order to develop strategies for mitigation and adaptation. There were 35 districts based on oilseeds cropping systems, 66 under cereals-based systems and 6 under pulses and 15 under various cash crops in India that were vulnerable to climate change (Figure 3). Vulnerable district were broadly classified into four categories depending upon dominant crop type prevalent there viz., oilseeds, cereals, pulses and cash crops. Major oilseeds were: soya bean, groundnut, mustard, castor and sunflower that were grown in northwest parts of Madhya Pradesh, western part of Rajasthan, north part of Gujarat, few patches in Karnataka, Andhra Pradesh and Telangana. Major crops among cereals were paddy, sorghum, maize, wheat, finger and pearl millet. Major parts of Rajasthan and Gujarat have large area under pearl millet and maize. Sorghum and finger millet are cultivated in central parts of Maharashtra. Paddy is a dominant crop in Chhattisgarh, Odisha, Karnataka, Telangana and Andhra Pradesh. Pulses like chickpea, green gram and red gram were prevalent in this region while cash crops like sugarcane, cotton and groundnut are dominant in parts of Rajasthan, Maharashtra and Madhya Pradesh.

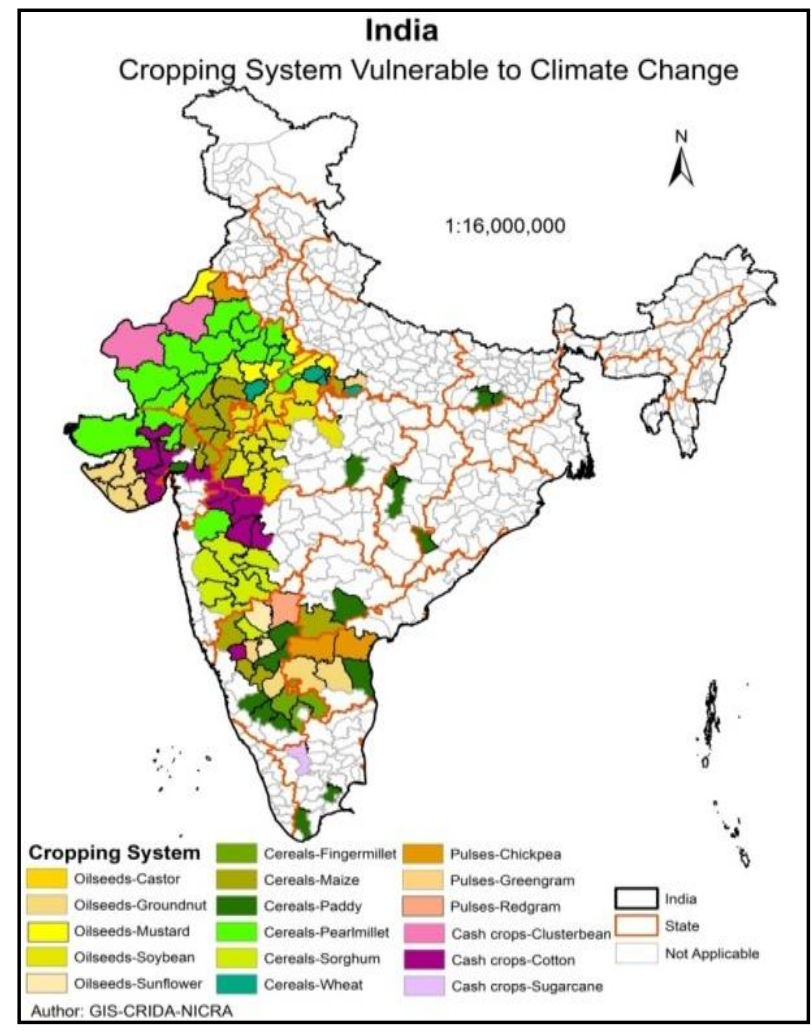

Figure 3: Cropping system prevalent in vulnerable districts in India

Variations in annual Max NDVI estimated (1982-2006) indicated a large variation in vegetation dynamics in the country owing to climatic variability. In arid regions in western Rajasthan and Gujarat and south-central India in
Bellary and Anantapur districts, vegetation cover was sparse but livestock population was large thus contributing to agricultural vulnerability especially due to drought. In the semi-arid and sub-humid zones which account for a large area under rainfed agriculture, natural resource base is poor owing to shallow soil cover and falling groundwater table, besides presence of large number of marginal and small farm holdings with heavy dependence on southwest monsoon rainfall leading to agricultural vulnerability. In the humid regions where two to three crops are cultivated annually, flood or drought could be devastating while in perhumid regions as in north-eastern region of India, a decline in rainfall could be harsh on the local economy. Study indicated that north-eastern region, western coastal plains, Sub- Himalayan hill region in Jammu \& Kashmir and Himachal Pradesh besides Eastern Plateau region in Chhattisgarh, Odisha and Jharkhand, have experienced a decline in NDVI.

\subsection{Typology Based on Variation in Length-of- Growing-Period (LGP) of Crops in India}

Types of variations in LGP like change in upper-limit (Figure 4) and in lower-limit in comparison to normal LGP estimated using FAO model (1982) were analyzed. LGP derived from FAO model were overlaid on those derived from AVHRR and MODIS NDVI datasets. Variations in lower-limit and upper-limit of LGP at AESR were analysed. Figure 4 indicates the variations in upper limit of LGP based on MODIS and AVHRR-NDVI datasets. In case of LGP derived from AVHRR-NDVI, it was seen that there was a change in upper-limit of LGP. For instance, there was a decrease in upper-limit of LGP in 44 districts in the semiarid parts of Madhya Pradesh and Maharashtra, increase in 70 districts in arid and semi-arid parts of Gujarat, Rajasthan and Karnataka and no change in 8 sub-humid districts in Karnataka. In case of variations in upper-limit of LGP based on MODIS- NDVI, it was seen that there was a decrease in 4 sub-humid districts in Chhattisgarh, an increase in 65 districts in the arid and semi-arid parts of Rajasthan, Gujarat and Karnataka and remained unchanged in 53 semi-arid districts in Madhya Pradesh, Karnataka and Maharashtra.

Change in lower-limit of LGP based on AVHRR \& MODIS-NDVI was analyzed by comparing it with LGP derived based on FAO Model. Figure 5 indicates that a decrease in LGP was recorded in 92 districts located mostly in Madhya Pradesh, Rajasthan and Gujarat in the semi-arid tract of India while an increase in LGP was noticed in 28 districts in Gujarat and Rajasthan in the arid region. No change in the lower-limit of LGP was recorded in two districts in arid parts of Karnataka. Analysis of LGP derived from MODIS-NDVI indicated that lower-limit had declined in 53 districts in semi-arid parts of Madhya Pradesh and Maharashtra and in arid region of Rajasthan. An increase was recorded in 60 districts in arid and semi-arid parts of Rajasthan, Gujarat and Karnataka. However no change in lower-limit of LGP was seen in 9 sub-humid districts located in Karnataka and Bihar. 
As illustration, in some of the vulnerable districts cropping systems and emerging LGP trends were analysed. In Gujarat for example, in Banas Kantha district where normal LGP was 60-90 days, study indicated an increase in upper limit of LGP to over 100 days which could translate as no threat of terminal drought to crops and also a possibility of cultivating crops requiring longer LGP than the traditional crops sown there. In Jalgaon district in Maharashtra located in Khandesh region in Nasik Division, the normal LGP of 120-150 days may decrease especially with reference to lower-limit of LGP. This could adversely affect the cultivation of banana crop for which the district is famous. In Prakasam district in Andhra Pradesh, normal LGP of 150180 days may decrease which could adversely affect cultivation of two major crops - paddy and groundnut. In Mandya district located in Bayaluseema or the open plains region in Karnataka, the normal LGP of 120-150 days may not change significantly indicating no adverse impact on the cropping systems prevalent therein.

Variability in LGP was seen to be high in regions having a LGP of <60 days and 120-150 days; it was lower in regions with LGP of 60-90 days and least in regions with 90-120 days.

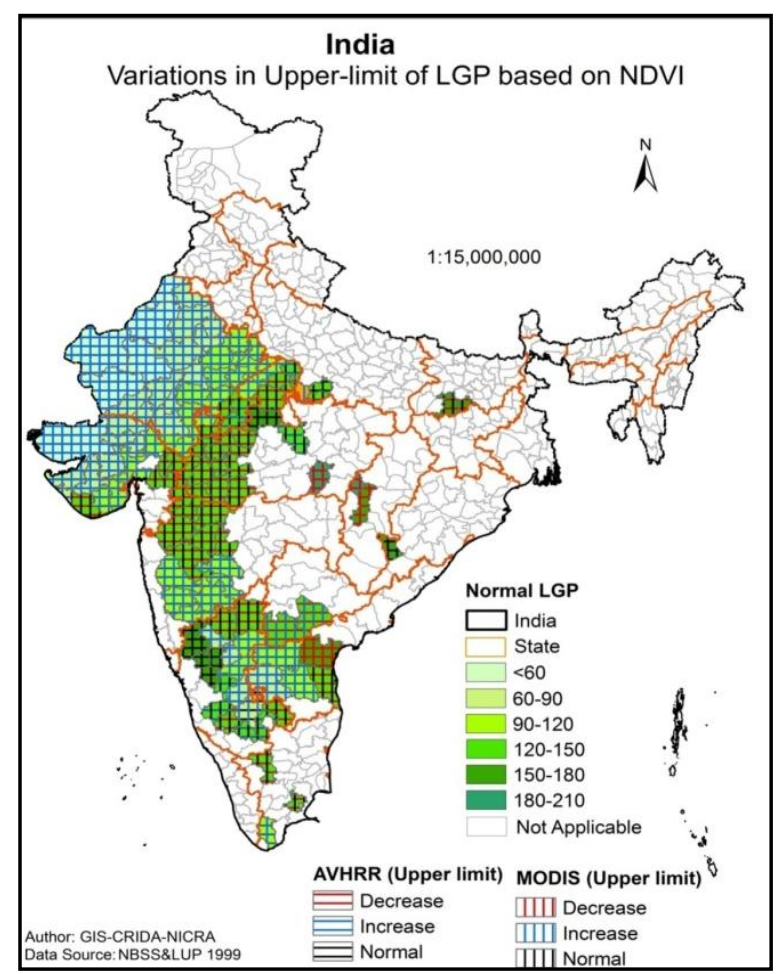

Figure 4: Change in upper - limit of LGP in comparison to normal LGP

Study also indicated a significant reduction in LGP during Rabi season. Increase in irrigation sources in several districts in central and southern India have led to a negative correlation between SPI and NDVI as in case of area with LGP of $90-120$ days where an increase in cultivated area was seen especially during Kharif season. Watershed development projects and water harvesting strategies have contributed to an increase in area under cultivation.

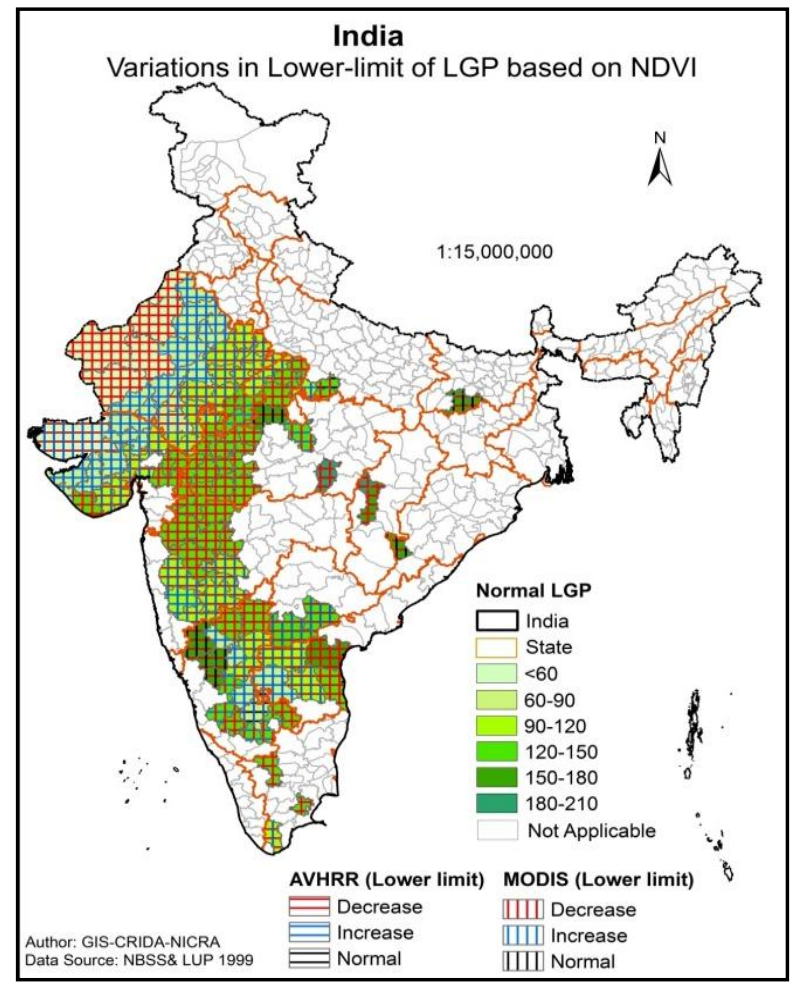

Figure 4: Change in lower-limit of LGP in comparison to normal LGP

\subsection{Implementation of Watershed Development Program for Improving Adaptation Capabilities of}

\section{Farmers}

Under a National Fellow scheme of ICAR at CRIDA, six critical indicators for sustainable agriculture through implementation of watershed development program were identified namely, increasing agriculture production and agricultural income, improving availability of fodder, maintaining Soil Water Conservation structures, adopting soil moisture conservation measures and farm organic matter recycling. It was seen that if these aspects were addressed effectively, agricultural vulnerability could be reduced. Study of numerous treated micro-watersheds indicated that the program imparted a positive but marginal benefit to agricultural sustainability or in other words addressed agricultural vulnerability (Kaushalya et al., 2009, 2013). It is evident that effective implementation of watershed development program and similar NRM programs besides socio-economic ones like MNREGS being implemented by Govt. of India could help improve adaptation capabilities of farmers.

\section{CONCLUSIONS}

Global datasets like NDVI data products from AVHRR and MODIS were found to be useful to assess agricultural vulnerability in India for which a methodology was developed using CV of Max NDVI. In order to understand the trend in NDVI variations, Standard Precipitation Index (SPI) was estimated for the corresponding time period in order to corroborate the results. 
Study indicated that over 122 districts covering 110 Mha encompassing over 26 agro-ecological sub-regions (AESR) in 12 states in the country were vulnerable to climate change. Of the 74 Mha under agriculture in these districts, MODIS dataset indicated that over 47 Mha of net sown area was vulnerable to climate change while AVHRR dataset with a coarse resolution indicated that over 29 Mha of net sown area was vulnerable to climate change. It is notable that nearly $1 / 5$ th to $1 / 3$ rd Net Sown Area in the country out of a total sown area of $142 \mathrm{Mha}$, is vulnerable to climate change.

Quantitative analysis of relationship between AVHRR $(8 \mathrm{~km})$ Mean and Max NDVI with actual rainfall occurrence in whole of India in two typical years i.e., 1982 \& 2006 revealed that while standard deviation of NDVI was less, it was higher in case of rainfall. Coefficient of variation of mean NDVI explained $8.1 \%$ of variation between the years. Between 1982 and 2006, there was only 5\% variation in AllIndia rainfall, $10 \%$ in case of Mean NDVI and $5 \%$ in case of Max NDVI. No clear-cut trend was discernable at the national-scale.

Typology based on agricultural vulnerability indicated that out of 122 districts identified over 30 were located in the arid zone, 81 in semi-arid and 11 in sub-humid bio-climatic zone. Based on cropping system it was seen that 64 of these districts were predominantly cereals growing, 37 oilseedbased, 15 cash-crop intensive and in 6 districts pulses cultivation was extensive. Analysis of livestock component indicated that in 69 districts large cattle were predominant while small ruminants were dominant in the rest.

It may thus be concluded that global datasets of satellite based NDVI were found to be a useful tool and a good indicator to assess agricultural vulnerability to climate change and its impacts. The datasets were useful to assess the slow change in agriculture and in identifying regions where agriculture could be vulnerable in future.

\section{REFERENCES}

[1]. Adger and Kelly (1999). Social vulnerability to climate change and the architecture of entitlements. Mitigation and adaptation strategies for global change 4: 253-266.

[2]. Aguilar, C., Julie C. Zinnert, María José Polo and D.R. Young (2012). NDVI as an indicator for changes in water availability to woody vegetation. Ecological Indicators 23: 290-300.

[3]. AICRPAM-CRIDA (2011). Weather cock@ V 1.0. NICRA.

[4]. Dadhwal, V.K. (2011). Retrieval of biophysical parameters from satellite data. (In): Agricultural drought: Climate change and rainfed agriculture (Eds. Rao, V.U.M., Rao, A.V.M.S., Kumar, P.V., Desai, S., Saikia, U.S., Srivastava, N.N. and B. Venkateswarlu). Lectures notes of the $5^{\text {th }}$ SERC School, CRIDA 52-58.

[5]. De Sherbinin, A., Chai-Onn, T., Giannini, A., Jaiteh, M., Levy, M., Mara, V. and L. Pistolesi (2014). Mali climate vulnerability mapping. Technical report for the
USAID African and Latin American resilience to climate change (ARCC) project. Washington, DC: USAID.

[6]. Fischer, G., Shah, M. and H. Van Velthuizen (2002). Climate change and agricultural vulnerability: A special report prepared by the international institute for applied systems analysis under United Nations institutional contract agreement no. 1113 Climate Change and Agricultural Vulnerability as a contribution to the World Summit on Sustainable Development.

http://www.accc.gv.at/pdf/JB-Report.pdf.

[7]. IPCC, (2007). Climate Change (2007). Impacts, Adaptation and Vulnerability. Contribution of Working Group II to the Fourth Assessment Report of the Intergovernmental Panel on Climate Change, M.L. Parry, O.F. Canziani, J.P. Palutikof, P.J. van der Linden and C.E. Hanson, Eds., 976pp.

[8]. IPCC, (2007a). Impacts, Adaptation and Vulnerability. Contribution of Working GroupII to the Fourth Assessment Report of the Intergovernmental Panel on Climate Change [Parry, M.L., O.F. Canziani, J.P. Palutik of, P.J. van der Linden, and C.E. Hanson (eds.)]. Cambridge University Press, Cambridge, UK and New York, NY.

[9]. IPCC, (2012). Managing the Risks of Extreme Events and Disasters to Advance Climate Change Adaptation. A Special Report of Working Groups I and II of the Intergovernmental Panel on Climate Change. Cambridge University Press, Cambridge, UK, and New York, NY, USA, $582 \mathrm{pp}$.

[10]. IPCC, (2013). Climate change 2013: The physical science basis. Working Group I contribution to the IPCC Fifth Assessment Report. Cambridge, United Kingdom: Cambridge University Press. www.ipcc.ch/report/ ar5/wg1. [11]. Kaushalya Ramachandran, Mandal, U.K., Sharma, K.L., Gayatri, M., Bhaskar. V., Srinivas. G., Venkatravamma, K and P. Karthik (2009). Methodology for Evaluating Livelihood Security of Farm Households in Treated Watersheds. Indian J. of Soil Conservation 37(2), 151-163.

[12]. Kaushalya Ramachandran (2013). Geospatial tools for Rainfed Agriculture. Geospatial World 4(2), 54-55.

[13]. Kaushalya Ramachandran, Gayatri, M., Praveen, V. and Satish, J. (2014a). Use of NDVI variations to analyse the length of growing period in Andhra Pradesh. J. of Agrometeorology 16(1), 112-115<http://modis.gsfc. nasa.gov/sci_team/pubs/abstract.php?id=09936>

[14]. Kaushalya Ramachandran, Praveen V., and S. Shubhasmita, (2014b). Assessing agricultural vulnerability in India using NDVI data products. International Archives of the Photogrammetry, Remote Sensing and Spatial Information Sciences, ISPRS Technical Commission VIII Symposium 40(8), 39-46<adsabs. harvard. edu/abs/2014ISPAr.XL8...39K>

[15]. Kaushalya Ramachandran, Shubhasmita S., Praveen V., Kalaiselvi, B., and J. Satish (2014c). Use of NDVI to Assess Variability in Length-of-Crop-Growing-Period Inducing Agricultural Vulnerability - a study of Telangana Region in Peninsular India. Global Environmental Research. Association of International Research Initiatives for Environmental Studies 18(2), 161-170. 
[16]. McKee, T. B., Doesken, N. J. and J. Kleist (1993).

The relationship of drought frequency and duration to time scales. $8^{\text {th }}$ Conf. On Applied Climatology, 17-22 January, Anaheim, CA, pp.179-184.

[17]. Murthy, C.S., SeshaSai, M.V.R., Chandrsekar, K. and P.S. Roy (2008). Spatial and temporal responses of different crop growing environments to agricultural drought-A study in Haryana state, India using NOAAAVHRR data. International J. of Remote Sensing.

[18]. Murthy C.S. and SeshaSai, M.V.R. (2011). Agricultural drought monitoring and Assessment. (In): Remote Sensing Applications (Eds. Roy, P.S., Dwivedi, R.S. and Vijayan, D.) NRSC/ISRO, 303-330, www.nrsc.gov.in.

[19]. SeshaSai, M.V.R., Murthy, C.S. and K.V. Ramana (2011). Agricultural drought assessment \& monitoring. (In): Agricultural drought: Climate Change and rainfed agriculture (Eds.Rao, V.U.M., Rao, A.V.M. S., Kumar, P.V., Desai, S., Saikia, U.S., Srivastava, N.N. \& B. Venkateswarlu), Lecture notes of the $5^{\text {th }}$ SERC school, CRIDA, 80-87.

[20]. TERI, (2003). Environmental threats, vulnerability and adaptation: Case studies from India. ISBN 81-7993042-4, 266p.

[21]. Thenkabail, P. S., Gamage, M. S. D. N. and V.U.Smakhtin (2004). The use of remote-sensing data for drought assessment and monitoring in Southwest Asia. Research Rpt. 85. Future Harvest, IMWI, 25p.

[22]. Tucker, C.J., Townshend, J.R.G. and T.E. Goff (1985). African land covers classification using satellite data. Science 227: 369-375.

[23]. US-EPA, (2014). Climate change indicators in the United States, 2014. Third edition. EPA 430-R-14-004 www.epa.gov/climatechange/indicators.

[24]. Velayutham, M., Mandal, D. K., Champa Mandal and J. Sehgal (1999). Agro ecological sub regios of India for planning and Development. NBSS\&LUP, Nagpur, India.Pub., p - 372. 